- Laboratory Work, including naked-eye and telescopic observations (for which they must set the telescope themselves, using coordinates and sidereal clock);

- Explicit Connections with the Humanities, in an effort to develop an appreciation of science that goes beneath the "gee whiz" level.

This is still in an early stage of development, but I am truly encouraged with how well the experiment is working out. Perhaps the most encouraging aspect of it is that students do not really consider it nearly as different as I do - they are accustomed to taking math courses, and this therefore looks very familiar to them. I therefore suspect that as a community we have simply overreacted to the declining quality of mathematics instruction in the schools; rather than opting to eliminate the quantitative content from our courses, we can instead adapt our teaching materials and syllabus to provide the increased support these students require.

\title{
COMPARATIVE METHODS FOR TEACHING AN ASTRONOMICAL TOPIC
}

\section{Syuzo Isobe}

National Astronomical Observatory, Osawa, Mitaka, Tokyo 181, Japan

Astronomy has greatly progressed in this decade. The number of people who are interested in astronomical phenomena is certainly increasing as the number of IAU members increases. These people are divided into several categories, depending on their degrees of interests. For Japan, these are as follows:

\begin{tabular}{ccl} 
Categories & $\begin{array}{c}\text { Rough Number } \\
\text { of People }\end{array}$ & \multicolumn{1}{c}{ Definition } \\
A & $10^{2}$ & produce useful observational data \\
B & $10^{3}$ & observe frequently \\
C & $10^{4}$ & observe several times per year \\
D & $10^{5}$ & read astronomical magazines \\
E & $10^{6}$ & read general science magazines \\
F & $10^{7}$ & read scientific articles in newspapers \\
G & $10^{8}$ & no interest in science
\end{tabular}

The situation is changed when some such special event, such as a return of Halley's comet, occurs. We can say that our present target in teaching astronomy is to increase the number of people in each category except the last one. 


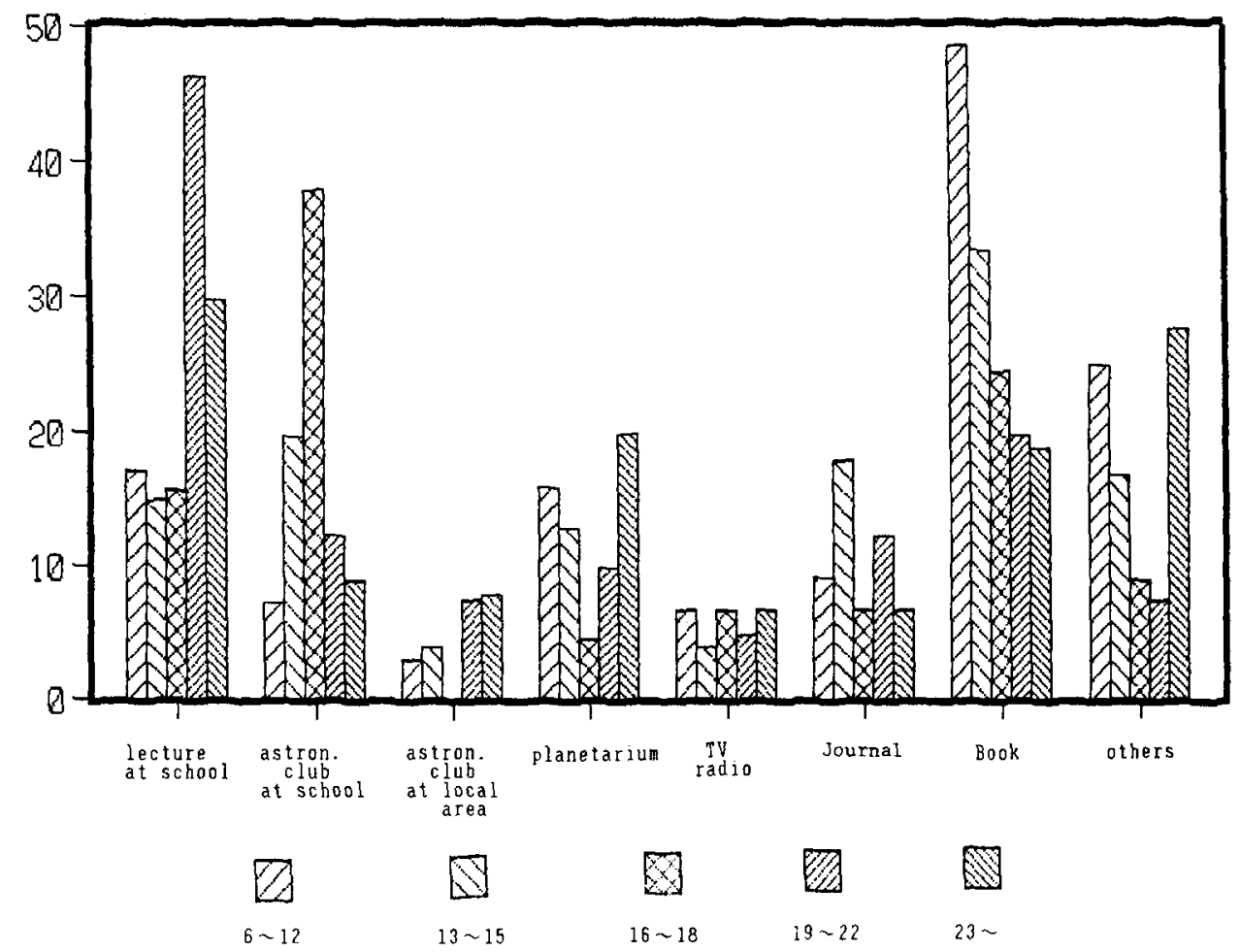

Fig. 1. Main triggers by which one started to be interested in astronomy.

Considering the above situation, astronomical and physical knowledge is also increasing for the general public, and it has become a popular idea not only that the Earth revolves around the sun, but also that stars form, evolve, and die. We sent a questionnaire to all the members of the Astronomical Society of Japan, and received 300 answers out of 700 . One of the results is shown in Fig. 1.

The number of people within each age group whose interest in astronomy was triggered by different items is shown in percentages. It is clear that the main trigger for children 6 to 12 years old was books that explain new discoveries in astronomy. These children sometimes know more about astronomical topics described in newspapers and magazines than do their teachers!

There are many branches of astronomy. Since a Hertzsprung-Russell (H-R) diagram is one of the most popular astronomical concepts, is very important to understanding evolution of stars, and has a secure position in astronomy, we compared methods for teaching about the H-R diagram. We compared the treatment of the $\mathrm{H}-\mathrm{R}$ diagram in 8 textbooks for Japanese senior high schools. Two examples are given in Fig. 2. 

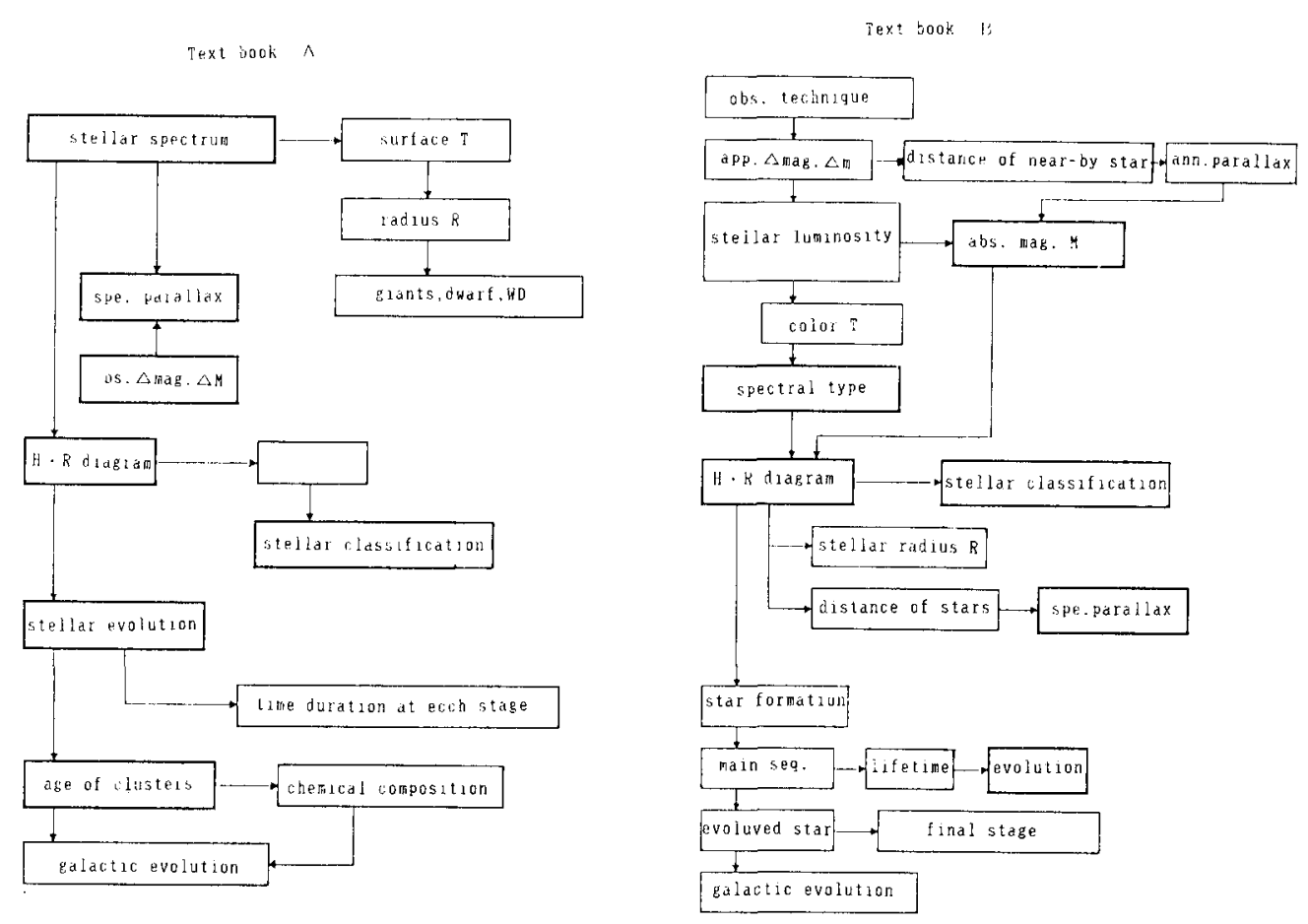

Fig. 2. Flow of teaching astronomy in two examples of textbooks.

All the textbooks have similar structure. First, stellar spectra and absolute magnitude are explained, an H-R diagram is drawn, and then a story of stellar evolution follows. This is a historical and orthodox sequence.

We also sent similar questionnaires to all the members of IAU Commission 46 (The Teaching of Astronomy) and obtained 32 answers (Table I). First, we asked what should be the order of astronomical topics to be taught at school and university. Most of the answers were in order of distance from Earth, that is, solar system, stellar system, and galactic structure and galaxies. This is also the historical sequence. About the H-R diagram, although nearly all the answers stressed its importance for studying stellar evolution, they used different parameters to draw an H-R diagram. For considering stellar evolution, one should use effective temperature and luminosity for the axes.

We also compared 11 English textbooks for undergraduate students available at our observatory. As shown in Fig. 3, different parameters are used from page to page in the 10 textbooks. Only one uses effective temperature and luminosity for the axes consistently throughout the book. 


\begin{tabular}{|c|c|c|c|c|c|c|c|c|c|c|c|}
\hline & & A & $B$ & C & $\mathrm{D}$ & $\mathrm{E}$ & $F$ & G & $\mathrm{H}$ & I & $\mathrm{J}$ \\
\hline \multicolumn{2}{|l|}{ consistency } & $x$ & 0 & $x$ & $\Delta$ & $\Delta$ & $x$ & $x$ & $\Delta$ & $\Delta$ & $x$ \\
\hline & & & & & & & & & & & \\
\hline $\mathrm{T}$ & $\mathrm{L}$ & & 0 & 0 & & 0 & & & & & \\
\hline$T$ & M & & & & & & & & & & 0 \\
\hline $\mathrm{T}$ & $L+M$ & & & & & & & 0 & & & \\
\hline$T+S p$ & M & & & & 0 & & 0 & & & & \\
\hline$T+S P$ & $L+M$ & & & & & & & & & 0 & \\
\hline$T+\operatorname{color}$ & $\mathrm{L}+\mathrm{M}$ & & & & 0 & & & & & & \\
\hline$T+S p+I$ & M & 0 & & & & & & & & & \\
\hline$T+S p+c 010 r$ & M & & & & & & & 0 & & & \\
\hline S p & $\mathrm{L}$ & & & & & & & & 0 & & \\
\hline $\mathrm{Sp}$ & M & 0 & & 0 & 0 & 0 & 0 & & & 0 & 0 \\
\hline S p & $L+M$ & & & & & & & 0 & & & \\
\hline $\mathrm{Sp}+\mathrm{C} \tau$ & $\mathrm{M}$ & & & $\mathrm{O}$ & & & & & & & \\
\hline C I & $\mathrm{L}$ & & & & & & & & 0 & & \\
\hline C I & $M$ & & & & & 0 & & & & & $\mathrm{O}$ \\
\hline $\mathrm{CJ}$ & $\mathrm{m}$ & & & & & & & & & & 0 \\
\hline color & M & & & & & 0 & & & & & \\
\hline
\end{tabular}

Fig. 3. Parameters used for both axes in 11 English textbooks. T: temperature, Sp: spectral type, c: color, and CI: color index. L: luminosity, M: absolute magnitude, $m$ : visual magnitude.

From Fig. 1, we see that many children already have some ideas on astronomical topics. It is good for them to understand the theoretical stellar evolutionary sequence. When this sequence is taught, theory and observation are compared. Such a comparison is also true for planetary motions. Children are taught those apparent motions in the sky assuming that they know the heliocentric motions of the planets.

Since the theory of stellar evolution is now settled, it may be the time for us to teach the $\mathrm{H}-\mathrm{R}$ diagram by first considering theoretical stellar evolution. It is interesting for me that one textbook is arranged in the order stellar system, galactic structure and galaxies, and solar system. The author intended to arrange it that way on the grounds that the theory of stellar evolution is settled. However, to teach galactic structure and galaxies, we should follow a historical sequence because these branches of astronomy are not completely settled at present.

Table 1 appears on page 108. 


\section{Discussion}

J.-C. Pecker: Your diagram about the triggering of interest for astronomy show that $T V$ is very inefficient in this respect. This is, I believe, a world-wide truth. I feel that we should put strong efforts in getting through $T V$ programs that could give good ideas about astronomy - not only about the objects or the facts, but also about the ways that astronomers use to reach knowledge.

T. Clarke: In response to Professor Pecker regarding the low level of TV in stimulating interest in astronomy, since television programs are selected by the viewers, those not having a prior interest in astronomy simply do not choose a program on astronomy. They select something else. Hence, we get a low indication of TV's value on the graph.

S. Isobe: One should remember that most of those who replied are the members of the Astronomical Society of Japan. I think that TV programs help the general public to enjoy astronomy and science.

D. McNally: If we are to take your survey at face value, then for greater effect we should advise that authors write only for 6-12 year olds and that lectures should only be given to 19-20 year olds.

S. Isobe: To simulate interest of pupils and students in astronomy, all kinds of the efforts contribute up to some level. I would like to say that each kind of the efforts work efficiently with the help of the other kinds of effort. 
Table 1. Answers from 32 members of IAU Commission ${ }^{a}$

\begin{tabular}{|c|c|c|c|c|c|c|c|c|c|c|c|c|c|c|c|c|}
\hline No & Country & $\begin{array}{l}1 \\
a b c d e\end{array}$ & $\begin{array}{l}2 \\
\mathrm{a}\end{array}$ & $\mathrm{b}$ & c & $\mathrm{d}$ & $\mathrm{e}$ & $\mathrm{f}$ & $\begin{array}{l}3 \\
\mathbf{a}\end{array}$ & $\mathrm{b}$ & $\mathrm{c}$ & $\mathrm{d}$ & $\mathrm{e}$ & $\begin{array}{l}4 \\
\mathrm{a}\end{array}$ & $\mathrm{b}$ & c \\
\hline 1 & Egypt & 31245 & $\mathrm{y}$ & $\mathrm{y}$ & $y$ & $\mathrm{y}$ & $\mathbf{y}$ & $\mathrm{y}$ & $y$ & $\mathbf{y}$ & $\mathrm{y}$ & & & $\mathrm{y}$ & $\mathrm{y}$ & $\mathrm{y}$ \\
\hline 2 & India & 41235 & $\mathrm{y}$ & $\mathrm{y}$ & $y$ & & & & $\mathrm{y}$ & $\mathrm{y}$ & & & & $\mathrm{y}$ & $\mathrm{y}$ & $\mathrm{y}$ \\
\hline 3 & Poland & y y y y y & $\mathrm{y}$ & & $\mathrm{y}$ & & & & $\mathrm{y}$ & & & & & $\mathrm{y}$ & & \\
\hline 4 & U.S.A & 21345 & $\mathrm{y}$ & & $\mathrm{y}$ & & $\mathbf{y}$ & & $\mathrm{y}$ & & & & & $\mathrm{y}$ & $\mathrm{y}$ & \\
\hline 5 & Yugoslavia & 12345 & $\mathrm{y}$ & $\mathbf{y}$ & $\mathrm{y}$ & $\mathrm{y}$ & & $\mathrm{y}$ & $\mathrm{y}$ & $\mathbf{y}$ & $\mathrm{y}$ & & & $y$ & & $\mathrm{y}$ \\
\hline 6 & Germany & 1234 & $y$ & & $\mathrm{y}$ & & & & & & $\mathrm{y}$ & & & $\mathrm{y}$ & $\mathrm{y}$ & \\
\hline 7 & Bulgaria & y y y y & $\mathrm{y}$ & & $\mathrm{y}$ & & & & $\mathrm{y}$ & & $\mathrm{y}$ & & & $\mathbf{y}$ & $\mathrm{y}$ & \\
\hline 8 & Australia & 41235 & & & $\mathbf{y}$ & & & & $\mathrm{y}$ & & $\mathrm{y}$ & & & $y$ & $\mathrm{y}$ & \\
\hline 9 & Poland & 21345 & & & $\mathrm{y}$ & & & & $\mathrm{y}$ & & & & & $\mathrm{y}$ & $\mathbf{y}$ & \\
\hline 10 & Finland & & & & & & & & & & & & & & & \\
\hline 11 & Indonesia & y y & & & $\mathrm{y}$ & & & & $\mathrm{y}$ & & $\mathrm{y}$ & & & $y$ & $\mathrm{y}$ & \\
\hline 12 & U.S.A. & $\mathrm{y} \quad \mathrm{y}$ & $\mathbf{y}$ & & $\mathrm{y}$ & & & & $\mathrm{y}$ & & $\mathbf{y}$ & & & $y$ & $\mathrm{y}$ & \\
\hline 13 & Australia & 14253 & $\mathbf{y}$ & $\mathrm{y}$ & $\mathrm{y}$ & & $\mathrm{y}$ & & $\mathrm{y}$ & $\mathrm{y}$ & & & & $\mathbf{y}$ & & $y$ \\
\hline 14 & U.K. & 2134 & $\mathbf{y}$ & $\mathrm{y}$ & $\mathrm{y}$ & & & & $\mathrm{y}$ & $\mathrm{y}$ & & & & $\mathrm{y}$ & $\mathrm{y}$ & y \\
\hline 15 & Malaysia & $\mathrm{y}$ & & & & & & & & & & & & & & \\
\hline 16 & U.K. & & $\mathbf{y}$ & $y$ & $\mathrm{y}$ & $\mathrm{y}$ & $y$ & $\mathbf{y}$ & $\mathrm{y}$ & $\mathrm{y}$ & $\mathrm{y}$ & $\mathbf{y}$ & & $\mathrm{y}$ & $\mathbf{y}$ & $\mathrm{y}$ \\
\hline 17 & U.S.A. & 12345 & $\mathbf{y}$ & $\mathrm{y}$ & $\mathrm{y}$ & & $\mathrm{y}$ & & $\mathrm{y}$ & $\mathrm{y}$ & $y$ & & & $\mathrm{y}$ & $\mathbf{y}$ & $y$ \\
\hline 18 & Switzerland & y y y y & $\mathrm{y}$ & $y$ & $\mathrm{y}$ & $\mathrm{y}$ & $\mathrm{y}$ & $\mathbf{y}$ & $\mathrm{y}$ & $\mathbf{y}$ & $y$ & & & $\mathrm{y}$ & $\mathbf{y}$ & $\mathrm{y}$ \\
\hline 19 & U.S.A. & 1234 & $\mathrm{y}$ & $\mathrm{y}$ & $\mathrm{y}$ & & $\mathrm{y}$ & $\mathbf{y}$ & $\mathrm{y}$ & $\mathrm{y}$ & $\mathrm{y}$ & & & $\mathrm{y}$ & $\mathrm{y}$ & $\mathrm{y}$ \\
\hline 20 & U.S.A. & 21345 & $\mathrm{y}$ & $\mathrm{y}$ & $\mathrm{y}$ & & $\mathrm{y}$ & $y$ & & & $\mathrm{y}$ & & & y & $\mathrm{y}$ & \\
\hline 21 & South Africa & & $\mathbf{y}$ & $\mathbf{y}$ & $\mathbf{y}$ & & & & $\mathrm{y}$ & $\mathrm{y}$ & & & & $\mathrm{y}$ & & $y$ \\
\hline 22 & Canada & y y y y y & $\mathrm{y}$ & $\mathrm{y}$ & $\mathrm{y}$ & $\mathrm{y}$ & $\mathrm{y}$ & $\mathrm{y}$ & $\mathrm{y}$ & $\mathrm{y}$ & $\mathrm{y}$ & & & & & \\
\hline 23 & Czechoslovakia & y y y & & $\mathbf{y}$ & $\mathrm{y}$ & & $\mathrm{y}$ & $\mathrm{y}$ & & & $\mathrm{y}$ & & & $\mathrm{y}$ & $\mathrm{y}$ & \\
\hline 24 & U.S.A. & 123 & $\mathrm{y}$ & & $\mathrm{y}$ & & & & $\mathrm{y}$ & & & & & $\mathbf{y}$ & $\mathrm{y}$ & \\
\hline 25 & U.S.A. & 1234 & $y$ & $\mathrm{y}$ & $\mathrm{y}$ & $\mathbf{y}$ & & & & & $\mathrm{y}$ & & & & $\mathrm{y}$ & \\
\hline 26 & Sweden & & $\mathrm{y}$ & $\mathrm{y}$ & $\mathrm{y}$ & $\mathrm{y}$ & $\mathrm{y}$ & $\mathbf{y}$ & $\mathrm{y}$ & $\mathrm{y}$ & $\mathrm{y}$ & $\mathrm{y}$ & & $\mathrm{y}$ & $\mathbf{y}$ & $\mathrm{y}$ \\
\hline 27 & France & y y y y & $\mathrm{y}$ & $\mathrm{y}$ & $\mathrm{y}$ & $\mathbf{y}$ & $\mathrm{y}$ & $\mathbf{y}$ & $\mathbf{y}$ & $\mathrm{y}$ & $\mathrm{y}$ & & & $y$ & $\mathrm{y}$ & $\mathrm{y}$ \\
\hline 28 & Hungary & y y y $y$ & $\mathrm{y}$ & & $\mathrm{y}$ & $\mathrm{y}$ & & $\mathrm{y}$ & $y$ & $\mathrm{y}$ & $\mathbf{y}$ & & & $\mathrm{y}$ & $\mathbf{y}$ & $\mathrm{y}$ \\
\hline 29 & Portugal & y y y y $y$ & $y$ & $\mathrm{y}$ & $\mathrm{y}$ & $\mathrm{y}$ & $\mathrm{y}$ & $y$ & $\mathrm{y}$ & & $\mathrm{y}$ & & & $\mathrm{y}$ & $\mathrm{y}$ & $\mathrm{y}$ \\
\hline 30 & Mexico & 21345 & $y$ & & & & & & & & $\mathrm{y}$ & & & & $\mathbf{y}$ & \\
\hline 31 & Australia & 12345 & $\mathbf{y}$ & $\mathrm{y}$ & $y$ & $\mathrm{y}$ & $\mathrm{y}$ & $\mathbf{y}$ & $\mathrm{y}$ & $\mathrm{y}$ & $y$ & $\mathrm{y}$ & $\mathbf{y}$ & $\mathbf{y}$ & $\mathrm{y}$ & $y$ \\
\hline \multirow[t]{2}{*}{32} & China & 12345 & $\mathrm{y}$ & $\mathrm{y}$ & $\mathrm{y}$ & & & & $\mathrm{y}$ & $\mathrm{y}$ & $y$ & $\mathrm{y}$ & & $\mathrm{y}$ & $\mathbf{y}$ & $\mathrm{y}$ \\
\hline & Total & & 26 & 19 & 29 & 11 & 14 & 13 & 25 & 16 & 22 & 4 & 1 & 27 & 25 & 16 \\
\hline
\end{tabular}

${ }^{a}$ Question 1: In what order of astronomical thema are pupils taught? a: Celestial dynamics, b: Solar system, c: Stellar physics, d: Galactic structure, e: Cosmology. Question 2: For what purpose is the H-R diagram taught? a: Classification of stars, b: Spectral type, c: Stellar evolution, d: Stellar mass, e: Spectroscopic parallax, f: Stellar radius. Question 3: What type of ordinate do you use? a: Absolute magnitude, b: Visual magnitude, c: Luminosity in solar units, d: Luminosity in ergs or eauivalent. e: others. Question 4: What type of abscissa do you use? a: Spectral type, b: Temperature, c: Color index (B-V 